\title{
Proteção jurídico-normativa da água
}

É senso comum que a água é um importante recurso natural, através do qual a vida no planeta é mantida, sendo responsável por hidratar os seres vivos, manter o equilíbrio da biodiversidade e permitir o desenvolvimento de diversas atividades pelos seres humanos. Diante da importância desse recurso natural e de sua crescente demanda objetivou-se analisar a legislação, doutrina e jurisprudência relacionadas à proteção dos recursos hídricos, e seu direito de uso no Brasil. A metodologia utilizada foi a histórico-jurídica, por meio do método de abordagem descritivo e explicativo. Traçou-se um panorama histórico do Direito das Águas do Brasil, passando pelo pioneiro Código das águas de 1934, que apesar de ter tido alguns de seus artigos revogados continua sendo uma referência jurídica importante, legislação esparsa que em alguns de seus dispositivos remetem aos recursos hídricos, notadamente na intenção de tutelar a sua qualidade, até chegarmos nas últimas décadas do século XX com a entrada em vigor da nova Política Nacional de Recursos Hídricos-PNRH, Lei 9.433/97 e seu Plano Nacional de Recursos Hídricos, que trouxe em seu bojo inovações relevantes para a gestão integrada e compartilhada dos recursos hídricos, fazendo uma abordagem dos recursos hídricos não só quanto aos aspectos qualitativo mas também quantitativo.

Palavras-chave: Código de Águas; Política Nacional dos Recursos Hídricos; Direito das águas; Direito de uso da água.

\section{Legal-normative protection of water}

It is common sense that water is an important natural resource, through which life on the planet is maintained, being responsible for hydrating living beings, maintaining the balance of biodiversity and allowing the development of various activities by human beings. Given the importance of this natural resource and its growing demand, the objective was to analyze the legislation, doctrine and jurisprudence related to the protection of water resources, and their right to use in Brazil. The methodology used was legal-historical, through the method of descriptive and explanatory approach. A historical overview of the Law of Waters of Brazil was traced, passing through the pioneering Water Code of 1934, which despite having had some of its articles revoked remains an important legal reference, sparse legislation that in some of its provisions refer to resources water resources, notably with the intention of safeguarding their quality, until we reached the last decades of the 20th century with the entry into force of the new National Water Resources Policy - PNRH, Law 9.433/97 and its National Water Resources Plan, which it brought in its bulge relevant innovations for the integrated and shared management of water resources, taking an approach to water resources not only in terms of qualitative but also quantitative aspects.

Keywords: Water Code; National Water Resources Policy; Water Law; Right to use water.

Topic: Legislação e Direito Ambiental

Reviewed anonymously in the process of blind peer.
Received: 02/12/2020

Approved: 25/02/2021
Juliana Aparecida Parcio (D)

Universidade Federal de Rondônia, Brasi http://lattes.cnpq.br/3388414799552705

http://orcid.org/0000-0002-1834-3453

parcioju@gmail.com

\section{Nubia Caramello id}

Fundação Universidade Federal de Rondônia, Brasil

http://lattes.cnpq.br/8155132371455051

http://orcid.org/0000-0002-2167-9759

geocaramellofri@gmail.com
Referencing this:

PARCIO, J. A.; CARAMELLO, N.. Proteção jurídico-normativa da água. Nature and Conservation, v.14, n.1, p.169-180, 2021. DOI: http://doi.org/10.6008/CBPC2318-2881.2021.001.0019 


\section{INTRODUÇÃO}

A água está presente nos oceanos, mares, calotas de gelo, geleiras, lagos, rios, solos e na atmosfera, na quantidade de cerca de 1.500 milhões de quilômetros cúbicos. Aproximadamente, $97 \%$ das águas são salgadas e constituem os oceanos e mares; $2,25 \%$ localizam-se nas calotas polares e geleiras; $0,72 \%$ se faz presente nos rios e lagos e uma ínfima quantidade na atmosfera (0,03\%) (SILVA, 2019). A análise desse percentual se converte relevante com a crescente densidade demográfica e com ela o consumo de recursos.

A água se converte no século XX um recurso de disputa e elemento essencial para a economia, passando a ser conhecida como recursos hídricos, estes são classificados em águas subterrâneas, composto pelos lençóis freáticos, localizados no subsolo e; em superficiais, aquelas "águas" que estão presentes na superfície da terra, como nos rios, lagos, mares, etc. (NUNES et al., 2016). Do ponto de vista jurídico, as "águas" podem ainda receber a classificação de internas ou interiores como os rios, lagos, mares interiores, o mar territorial, os portos, canis e ancoradouros, as baías, golfos e estuários; e, em externas que são as águas contíguas e o alto-mar (CASELLA et al., 2009).

A água é um bem indispensável à vida animal e vegetal, pois compartilha dos processos fisiológicos essenciais, a exemplo tem-se a fotossíntese no reino vegetal e a respiração presente tanto no reino vegetal quanto animal. De forma complementar, funciona como habitat e nicho ecológico de inúmeras espécies animais e vegetais. Suas características físico-químicas de mobilidade, solubilidade, variação de densidade, regulação térmica e especialmente sua tensão superficial são atributos que respondem por sua extraordinária função nos ecossistemas naturais e agroecossistemas alterados pela sociedade (PENMAN, 1948).

De acordo com o World Resource Institute (WRI) nas próximas duas décadas, aproximadamente 161 países terão grandes desafios e conflitos provocados pela escassez da água. Cidades podem entrar em colapso, sem condições básicas de abastecimento humano e serviços, hospitais, equipamentos públicos, fábricas podem precisar fechar suas portas por falta de água (ONU, 2020).

Neste contexto, o estado brasileiro é a nação que possui maior reserva de água doce do mundo, porém o seu uso ocorre, frequentemente de modo irracional em todo País. O que tem proporcionado irregularidade no suprimento de água na maioria das bacias do Nordeste, na grande São Paulo e regiões pontuais dos estados de Minas Gerais, Bahia e Rio Grande do Sul (WOLKMER et al., 2013).

Apesar de o Brasil possuir a maior reserva de água doce do mundo (16\% do total), sua distribuição caracteriza-se por ser muito desproporcional entre as regiões brasileiras e, principalmente em relação à densidade populacional. Por exemplo, do total de água doce no Brasil, $68 \%$ está localizada na região norte que possuí menor densidade demográfica do País $\left(4,5\right.$ habitantes $\left.\mathrm{km}^{-2}\right)$ em contraste aos $6 \%$ da água doce presente na região sudeste que possuí a maior densidade demográfica do Brasil $\left(94,86\right.$ habitantes $\left.\mathrm{km}^{-2}\right)$. E, o Nordeste caracteriza-se por ser a região que possui menor disponibilidade de água doce, contando com apenas $3 \%$ do total e, densidade demográfica de $\left(36,39\right.$ habitantes $\left.\mathrm{km}^{-2}\right)$ (IBGE, 2018).

Ainda que a região Norte apresente o maior percentual de água doce superficiais do Brasil, esse fato 
não garante a ausência de escassez e tampouco a ausência de conflito pelo direito de acesso e uso desse recursos, tomemos como exemplo os conflitos anunciados pelos índios do Xingu (Pará), da Terra do Sol (Roraima) e dos que vivem nas Terras Indígenas da Bacia do Rio Branco (Rondônia), em comum eles tem a árdua luta para garantir o direito aos territórios e seus rios que se encontram ameaçados direta ou indiretamente pela implantação de empreendimentos hidroelétricos (CARAMELLO et al., 2016).

Diante da importância da para o planeta e dos recursos hídricos para a economia global e da possibilidade da sua real escassez em curto espaço de tempo no cenário mundial, denota-se a relevância de uma estrutura jurídica-normativa sólida para sua proteção e assegurar o direito atribuído a todos os atores. Neste sentido, objetivou-se analisar a atuação do Estado na proteção dos recursos hídricos, enfatizando os aspectos político-jurídicos da presença estatal, por meio da análise da evolução da estrutura legal de proteção às águas, principalmente no que diz respeito ao seu aspecto quantitativo, sem ignorar que existe, ainda, um viés mercantilista, no qual a água é importante para indústrias, empresas, sistemas de irrigação e tantos outros exemplos que poderiam ser trazidos e que demonstram a necessidade da sua preservação para o desenvolvimento e para a manutenção de todas as formas de vida no planeta terra.

\section{METODOLOGIA}

Para tanto, o método de abordagem utilizado para a pesquisa é o descritivo e explicativo, com uma metodologia histórico-jurídica (MEZZAROBA, 2009). As técnicas eleitas para cumprir o caminho cognitivo mencionado é a pesquisa bibliográfica, tendo por referência, leis, doutrinas, jurisprudências e tratados internacionais (ODAR, 2016).

Desse modo, o artigo está contextualizado, a partir de quatro sessões: i) Competência para legislar sobre recursos hídricos; ii) Legislação esparsa; iii) Código de Águas; iv) Política nacional de recursos hídricos; v) Direito de uso das águas.

A análise do conteúdo de Bardin (2011) foi a luz para as interpretações do conjunto de dados, que tem sua categoria de analise centrada na Água, enquanto protagonista presente em leis, decretos e políticas públicas governamental.

\section{DISCUSSÃO TEÓRICA}

\section{Competência para Legislar Sobre Os Recursos Hídricos}

A constituição é centralizadora nessa matéria, dispondo em seu artigo 22 IV, que cabe à União legislar privativamente sobre águas, podendo ela submeter todas as águas a um rígido controle público, especialmente visando à sua preservação e proteção jurídica contra as formas de degradação (SILVA, 2019).

É competência da União editar Normas Gerais sobre Recursos Hídricos e aos Estados e Distrito Federal editar normas suplementares, sendo competência comum de todos os entes federados: União, Estados, Distrito Federal e Municípios proteger o meio ambiente e combater a poluição em qualquer de suas formas (BRASIL, 1988). 
A Gestão dos recursos hídricos também encontra amparo constitucional, no artigo 21 da Constituição Federal de 1998 (CF/88) que estabelece ser competência da União instituir o sistema nacional de gerenciamento de recursos hídricos e definir critérios de outorga de direitos para seu uso (BRASIL, 1988). A Lei 9.4333/97 que dedica as diretrizes e instrumentos para a gestão hídrica, é a base da formulação das leis das águas elaboradas pelos Estados brasileiros.

\section{Legislação Esparsa}

Inúmeras são as leis do ordenamento brasileiro que tratam de águas, o que reforça a falsa ideia de que o regime jurídico de proteção possui legislação suficiente para preservá-la, porém a essência da conservação deste recurso não está restrita às leis, mas à conscientização de sua importância ou até em um planejamento mundial. Fato que levou a Organização das Nações Unidas a inseri-la em um dos seus 17 (dezessete) Objetivos de Desenvolvimento Sustentável a ODS6 que dedica a Água Potável e Saneamento, objetivando assegurar esse bem natural a todos (ONU, 2020).

A grande maioria dos diplomas legais que versão sobre a proteção das águas se preocupou em protege-la em seu aspecto qualitativo, ou seja, a poluição dos recursos hídricos sempre foi uma preocupação para o legislador pátrio. O próprio Código das Águas contém normas nesse sentido, como a do art. 68, que submete à inspeção administrativa: a) as águas comuns e os particulares, no interesse da saúde e da segurança; b) as águas comuns, no interesse dos direitos de terceiros, ou na qualidade, curso ou altura das águas públicas (BRASIL, 1934).

A proteção jurídica, conforme Silva (2019) das águas se faz presente nos mais diversos diplomas legais, como por exemplo no Código Penal que em seus artigos 270 e 271 prevê a proteção das águas potáveis contra envenenamento, corrupção ou poluição, entendendo-se como água potável aquela isenta de elementos insalubres e adequada para o consumo humano.

Depois veio o Código Nacional de Saúde (Decreto 49.974-A de 21 de janeiro de 1961, regulamentando a Lei 2.312, de 03 de setembro de 1954, que também trouxe disposições de proteção dos recursos hídricos, dispondo que os resíduos líquidos, sólidos ou gasosos domiciliares ou industriais, somente poderiam ser lançados às águas, in natura ou depois de tratados, quando essa operação não implicasse poluição das águas receptoras (SILVA, 2019).

Em 1962 foi a vez da lei 4.089 que atribuiu ao Departamento Nacional de Obras e Saneamentos a competência para controlar a poluição das águas no âmbito federal.

Além das leis acima mencionadas, merecem referência nesta pesquisa, por seu caráter de tutela ambiental, a legislação que segue: a) Decreto n²3.793 de 23.01.1.934 - Código Florestal; b) Decreto Lei n² 2.848 de 07.12.1940 - Código Penal; c) Lei n 4.504 de 30.11.1.964 - Estatuto da Terra; d) Lei n 4.771 de 15.09.1.965 - Código Florestal; e) Lei $\mathrm{n}^{\circ} 5.357$ de 17.11.1.967 - Estabelece penalidades para embarcações que lançarem detritos ou óleo em águas brasileiras; f) Lei n 6.766 de 19.12.1.979 Parcelamento do solo urbano; g) Lei n 6.938 de 31.08.1.981 - Lei da Política Nacional do Meio Ambiente h) Lei n 7.347 de 24.07.1.985 - Ação Civil Pública. 
Não se esgota a contribuição legal com a legislação citada, sem embargo evidencia-se que a água vem sendo protagonista no diálogo legal em diferentes segmentos. Sendo habitualmente o Código das Águas e a Lei 9.433/97 sendo as mais citadas quando a pauta é gestão de recursos hídricos, e sobre eles se destinará em separado os próximos dois tópicos.

\section{Código das Águas}

Desde de 1934 o legislador vem-se preocupando com a proteção das águas contra a poluição. O código das águas, aprovado pelo Decreto 24.643 , de 10.7.1934, mantido e modificado pelos Decretos-lei 852/1938 e 3.763/1941, faz uma classificação imprópria das águas em águas públicas, águas comuns e águas particulares (SILVA, 2019).

Porém essa ideia de água particular encontra-se superada pela Constituição Federal de 1988, que em seu artigo 22, IV afirma que cabe à União legislar privativamente sobre águas, podendo submeter todas as águas a um rígido controle público, especialmente visando à sua preservação e proteção jurídica (BRASIL, 1988).

A Lei Brasileira de Águas que remonta a 1934: o Código das Águas, adveio, principalmente, e consoante Corrêa (2005), da demanda das companhias elétricas que estavam nascendo e se viam limitadas pelo fato de os poderes concedentes de aproveitamento dos recursos hídricos serem exclusivamente dos estados e municípios.

Nessa seara, a água era tradada como bem público, todos tinham direito de utiliza-la conforme suas necessidades. E a depender do uso que se fazia da água sua derivação dependia de concessão quando a utilidade era pública ou de autorização para os demais usos. De modo que a política era concebida para cada tipo de usuário e paulatinamente passou-se a dar grande importância à geração de energia para a promoção do desenvolvimento.

Considerado o marco regulatório das águas, o Código das Águas enfoca o recurso hídrico enquanto dotado de valor econômico e surgiu, especialmente, em razão da necessidade de regulamentar o uso da água e sua uma demanda no setor elétrico. É o que se pode depreender das palavras inaugurais:

Considerando que o uso das águas no Brasil tem-se regido por uma legislação obsoleta, em desacordo com as necessidades e interesse da coletividade nacional; Considerando que se torna necessário modificar esse estado de coisas, dotando o país de uma legislação adequada que, de acordo com a tendência atual permita ao Poder Público controlar e incentivar o aproveitamento industrial das águas; Considerando que, em particular, a energia hidráulica exige medidas que facilitem e garantam seu aproveitamento racional; (...) Resolve decretar o seguinte Código de Águas [...]. (BRASIL, 1934)

O Decreto $n^{\circ} 24.643 / 34$ está dividido em três livros: I Águas em geral e sua propriedade; II Aproveitamento das águas; III Forças hidráulicas - regulamentação da indústria hidroelétrica.

O Livro I classifica as águas quanto ao seu domínio em águas públicas, águas comuns e águas particulares. O Livro II, em seu Art. 34 assegura, para as águas comuns de todos, o uso gratuito de qualquer corrente ou nascente de águas para as primeiras necessidades da vida, se houver caminho público que o torne acessível. O Art. 36 permite a todos usar de quaisquer águas públicas desde que em conformidade 
com os regulamentos administrativos, e assegura o uso prioritário para o abastecimento das populações.

Tem-se no Art. 43 a definição de que as águas não podem ser derivadas para as aplicações da agricultura, da indústria e da higiene, sem a existência de concessão administrativa. Pode-se se dizer que o art. 43 do Código das Águas é o precursor do que mais tarde, na atual Lei das águas, é tratado como Outorga de uso de água.

O Título IV trata das águas subterrâneas, inclusive no que diz respeito à sua poluição: são expressamente proibidas construções capazes de poluir ou inutilizar para o uso ordinário a água do poço ou nascente alheia a elas preexistentes. Por sua vez, o Título VI aborda também o tema poluição, a saber: a ninguém é licito conspurcar ou contaminar as águas que não consome, com prejuízo de terceiros.

O Livro III aborda as forças hidráulicas e a regulamentação da indústria hidrelétrica. Em seu Art. 139 estabelece o aproveitamento das quedas de água e na sequência define as competências do Serviço de Águas do Departamento Nacional de Produção Mineral do Ministério da Agricultura.

O Código de Águas, em seu Art. 143, sinaliza para o uso múltiplo dos recursos hídricos, como também o faz a atual Lei das águas, tais como: em todos os aproveitamentos de energia hidráulica serão satisfeitas exigências acauteladoras dos interesses gerais da alimentação e das necessidades das populações ribeirinhas, da salubridade pública, da navegação, da irrigação, da proteção contra inundações, da conservação e livre circulação do peixe, e do escoamento e rejeição das águas.

Na parte final, ao tratar das disposições gerais, o Art. 200 estabelece que será criado um Conselho Federal das Forças Hidráulicas e Energia Elétrica, além de definir suas atribuições (BRAGA et al., 2006).

Inovador, o Código de Águas estabeleceu uma política hídrica moderna e complexa, levando em consideração a época de sua edição, segundo um autor este estatuto de águas é, mundialmente, considerado uma lei de águas completa, sendo que os princípios ali insculpidos servem de modelos a serem seguidos por diversos países.

Atendendo ao contexto histórico, no qual havia grande preocupação com a promoção do desenvolvimento, principalmente das industrias, desenvolver leis que facilitassem a geração de energia era estratégico, de maneira que o principal enfoque do Código das águas eram os recursos hídricos com potencial hidrelétrico.

A tutela jurídica das águas sempre apareceu circunstancialmente em alguns diplomas legais e como tema principal no Código das águas, porém somente com a consciência da gravidade da degradação do meio ambiente natural (águas), cuja proteção passou a reclamar uma política deliberada, mediante normas diretamente destinadas a prevenir, controlar e recompor sua qualidade e em mais uma tentativa de se proteger juridicamente a água em 1997 o Legislador editou a Lei № 9.433 e implantou a atual Política Nacional dos Recurso Hídricos (BRASIL, 1997).

\section{Política Nacional dos Recursos Hídricos}

A lei 9.433, de agosto de 1997, instituiu a Política Nacional de Recursos Hídricos (PNRH), o que significa dar organicidade e sistemática às formas de proteção dos recursos hídricos brasileiros para além da 
simples proteção contra poluição, como se pode observar nas legislações que a antecederam.

A PNRH em seu artigo inaugural fundamenta-se no fato de ser a água um bem de domínio público, ser um recurso natural limitado, dotado de valor econômico e que em situação de escassez, seu uso deve ser prioritariamente o consumo humano e matar a sede de animais. Preconiza a gestão de recursos hídricos de forma descentralizada e participativa do Poder Público, dos usuários e das comunidades, primando sempre pelo uso múltiplo das águas (BRASIL, 1997).

Os objetivos da Lei estão definidos no artigo 2º, que semelhante a Constituição Federal de 1988 em seu artigo 225, visa assegurar à atual e às futuras gerações a necessária disponibilidade de água, em padrões de qualidade adequados aos respectivos usos; a utilização racional e integrada de recursos hídricos, incluindo o transporte aquaviário, com vistas ao desenvolvimento sustentável; a prevenção e a defesa do uso inadequado dos recursos naturais e incentivar e promover a captação e o aproveitamento de águas pluviais, sendo que este último objetivo foi incluído por meio da lei 13.501 de 2017.

Consoante, Santilli (2007) a lei traz ainda importantes diretrizes de ação para implantação da PNRH, sendo eles gestão sistemática dos recursos hídrico, sem dissociação dos aspectos de qualidade e quantidade; a adequação da gestão de recursos hídricos às diversidades físicas, bióticas, demográficas, econômicas, sociais e culturais das diversas regiões do país; a integração da gestão de recursos hídricos com a gestão ambiental articulando o planejamento de recursos hídricos como o dos setores usuários e com os planejamentos regionais, estadual e nacional ; articulação da gestação o dos recursos hídricos com o uso do solo; a integração da gestão das bacias hidrográficas com dos sistemas estuarinos e zonas costeiras. E ainda em seu artigo 40 estabelece a articulação da União e Estados tendo em vista o gerenciamento dos recursos hídricos.

A PNRH em seu artigo V elege a bacia hidrográfica como unidade territorial para a aplicação da lei, o que se tornou um dos maiores desafios para a sua implantação, mas sem dúvida uma escolha sábia em virtude da indivisibilidade dos recursos hídricos presente na bacia.

Ainda conforme, Antunes (2001) aos problemas relacionados aos recursos hídricos não podem ser enfrentados desconsiderando as realidades geográficas. A adoção da gestão por bacias é um passo fundamental para que se consiga um padrão ambientalmente aceitável para os nossos recursos hídricos.

Igualmente relevante é a adoção do critério de gestão compartilhada e descentralizada dos recursos hídricos, pois sendo um elemento de interesse de toda a sociedade, ações conjuntas favorecem a obtenção de resultados favoráveis, uma vez que é do interesse coletivo de todas as pessoas físicas e jurídicas, de direito público e privado a melhor gestão, para melhor aproveitamento e distribuição dos recursos hídricos.

A já mencionada gestão descentralizada das águas, ponto que merece destaque na lei, que deve contar com a participação do Poder Público, dos Usuários e da Sociedade Civil Organizada, de forma que todos os setores que dependem da utilização dos recursos hídricos serão responsáveis por sua gestão, na forma de Comitês de Bacias institucionalizados, das Agências de Água e dos Conselhos Estaduais e Nacionais de Recursos Hídricos. 
Os instrumentos da PNRH que estão elencados no seu art. 5. são compostos por: a) planos de recursos hídricos; enquadramento dos corpos de água em classes, segundo os usos preponderantes da água, cabendo à legislação ambiental o estabelecimento dessas classes (art. 10, Lei no 9.433/97); b) outorga dos direitos de uso dos recursos hídricos; cobrança pelo seu uso; c) compensação a municípios e sistema de informações sobre recursos hídricos (BRASIL, 1997)

Segundo Rodrigues (2008) tais instrumentos têm por função dar aos gestores condições necessárias para traçarem as diretrizes específicas de ação para gerir os recursos previstos na lei. Configuram, portanto, ferramentas de aplicação prática do presente diploma legal. Importante destacar ainda que não se trata de um rol taxativo, ou seja, nada impede que na prática sejam lançadas mãos de outros instrumentos não previsto na lei, caso sejam necessários e viável.

Os planos previstos nos artigos 6ㅇ e 70 da lei são instrumentos de planejamento estratégico da respectiva bacia hidrográfica, que se atém tanto às necessidades ambientais, econômicas e sócias, sendo que o prazo de duração dos planos deverá ser o maior possível, com o objetivo de implementar políticas de curto, médio e longo e longo prazos que assegurem que todos os projetos e programas serão de fato implementados.

Outra relevante inovação trazia pela Lei das Águas foi a criação do Sistema Nacional de Gerenciamento dos Recursos Hídricos (SNGRH), regulamentando o inciso XIX do artigo 21 da Constituição Federal, e conforme Wolkmer et al. (2013) o PNRH é considerado um instrumento orientador da gestão, com um caráter de construção permanente, fruto da participação e do diálogo multidisciplinar, envolvendo as dimensões, nacional, estadual e local.

Também é fruto da PNRH o Conselho Nacional de Recursos Hídricos (CNRH), órgão máximo do SNGRH, ao qual o legislador conferiu papel normativo, é um grupo colegiado responsável por desenvolver regras de mediação entre os diversos usuários da água, caracterizando-se como o maior responsável pela implementação da gestão dos recursos hídricos no País.

É competência do Conselho, conforme artigo 35 da Lei no 9.433/97: a) promover a articulação do dos setores usuários; b) arbitrar, em última instância administrativa, os conflitos existentes entre conselhos estaduais de recursos hídricos; c) deliberar sobre os projetos de aproveitamento dos recursos hídricos cujas repercussões ultrapassem os limites dos Estados onde serão instalados; d) deliberar sobre questões encaminhadas pelos conselhos Estaduais ou pelos Comitês de Bacia Hidrográfica; e) analisar propostas de alteração na legislação sobre recursos hídricos e na Política Nacional de Recursos Hídricos; f) estabelecer diretrizes complementares para implementação da Política Nacional, aplicação dos seus instrumentos e atuação do Sistema Nacional de Gerenciamento Recursos Hídricos; g) aprovar propostas de instituição de CBH e estabelecer critérios gerais para a elaboração de seus regimentos; h) aprovar propostas de instituição de Comitês de Bacia Hidrográfica e estabelecer critérios gerais para a elaboração de seus regimentos; i) acompanhar a execução do Plano Nacional de Recursos Hídricos e tomar providências para o cumprimento de suas metas; j) estabelecer critérios gerais para a outorga do direito de uso dos recursos hídricos. 
Segundo Guedes (2009) o CNRH é o principal fórum de discussão nacional sobre gestão de recursos hídricos, exercendo o papel de agente integrador e articulador das respectivas políticas públicas, particularmente quanto à harmonização do gerenciamento de águas de diferentes domínios.

Os Comitês de Bacia Hidrográfica é parte integrante do Sistema Nacional de Gerenciamento de Recursos Hídricos e conforme Enkes (2013) possuem atribuição de verdadeiros parlamentares perante sua área de atuação. A composição diversificada e democrática dos Comitês contribui para que todos os setores da sociedade com interesse sobre a água na bacia tenham representação e poder de decisão sobre sua gestão. Os membros que compõem o colegiado são escolhidos entre seus pares, sejam eles dos diversos setores usuários de água, das organizações da sociedade civil ou dos poderes públicos. Suas principais competências são: aprovar o Plano de Recursos Hídricos da Bacia; arbitrar conflitos pelo uso da água, em primeira instância administrativa; estabelecer mecanismos e sugerir os valores da cobrança pelo uso da água; entre outros, conforme o artigo 38 da lei.

As Agências de Água exercerão a função de secretaria executiva do respectivo ou respectivos Comitês, são órgãos com personalidade jurídica, criadas para dar apoio técnico aos Comitês e arrecadar e gerir os recursos advindos da cobrança pelo uso da água. Conforme dados da Agência Nacional de Águas já foram instituídos por meio de decretos estaduais 197 comitês (ANA, 2015).

A intenção do legislador em regular todos os quesitos provenientes da água e sua realidade quanto ao uso e a demanda social é de grande valia e quando aplicada atinge o objetivo essencial da norma, que é promover o uso sustentável dos recursos hídricos, sem dúvida muitas forram as inovações trazidas pela PNRH. Conforme Tucci (2005) ela introduziu na doutrina e na prática critérios realmente renovadores.

A referida lei, também foi a base da elaboração dos instrumentos legais construídos pelos Estados, como exemplo destaca-se o estado de Rondônia quem em 25 de janeiro 2002, formulou a Lei Complementar 255, instituindo o Sistema de Gerenciamento e o Fundo de Recursos Hídricos do Estado de Rondônia (CARAMELLO et al., 2019). Relevante observar que a elaboração da lei, não garante de imediato a implantação de suas diretrizes como ocorreu com o comitê de bacias hidrográficas do Estado de Rondônia que somente foi implantado no ano de 2014 a partir de cinco decretos, estando o surgimento dos comitês vinculados a presença de conflitos pelo uso e direito a água, nas cinco unidades de gestão criadas.

O direito pelo uso da água, com necessidade de ser outorgado ou não é um dos pontos que convertem a água em recurso econômico, e quando a ausência de direito é sentido pelos atores hidrográficos de uma bacia inicia-se o processo de conflito seja pela construção de hidrelétricas, implantação do agronegócio como ocorre na Bacia Hidrografia do Rio Teles Pires no Mato Grosso (FIGUEREDO, 2019) ou pela construção de Pequenas Centrais Hidroelétricas que compromete a navegação e a pesca dos povos indígenas na Bacia Hidrografia do Rio Branco e Colorado no Estado de Rondônia (LIMA et al., 2019). 


\section{Direito de Uso das Águas}

A esse respeito à Constituição Federal de 1988 em seu artigo 20, inciso III deu à água o status de bem de domínio público, também chamado de bem de uso comum do povo, o que de fato representa um importante avanço, status este que foi reafirmado pela Política Nacional de Recurso Hídricos em 1997.

O artigo constitucional supracitado (artigo 20, inciso III ), em conjunto com o artigo 26 estabelecem quais águas são de domínio de União e quais são de domínio dos Estado, sendo que as que banhem mais de um Estado, sirvam de limites com outros países, se estendam a território estrangeiro ou dele provenham, bem como os terrenos marginais e as praias fluviais são de domínio da União, sendo de domínio dos Estados e do Distrito Federal as superficiais ou subterrâneas, e rios e lagos que não ultrapassem o limite de um Estado.

Sendo que a gestão dos recursos hídricos, bem como a outorga do uso da água encontra amparo constitucional, o artigo 21 da CF/88, o qual estabelece ser competência da União instituir o sistema nacional de gerenciamento de recursos hídricos e definir critérios de outorga de direitos para seu uso.

Direito de uso é um instrumento jurídico de direito administrativo, por meio do qual a administração pública atribui a outrem, o direito de uso de um bem que é público (ALEXANDRINO et al., 2009), de maneira que a outorga não transmite ao particular a propriedade da água, mas tão somente o direito de usá-la privativamente, sei que esse uso impeça a utilização dos demais usuários.

Consoante Silva (2019) O direito de uso da água por terceiros depende da análise de conveniência e de oportunidade administrativa de delegar a outrem o uso de um bem que por força de lei é considerado de domínio público.

Para Barreto (2019) a legislação precisa estar atenta as características territoriais, o que reforça a pertinência da unidade de gestão hídrica ser a delimitação de uma bacia hidrográfica conforme proposto pela Lei $9.433 / 97$, sem mencionar a qual dimensão territorial deve ter essa unidade de gestão. No caso da Amazônia Barreto (2019) propõem a leitura de direitos das comunidades tradicionais, povos indígenas a partir do direito ao que ela semelhante a Nunes et al. (2016) intitulou do "Território das Águas". Sendo a água um bem coletivo.

Desta forma o particular apesar de não ser dono da água, poderá fazer uso privativo desse recurso natural por meio da outorga, diz então que o particular tem o Direito de uso.

\section{CONCLUSÕES}

Relativamente à proteção jurídica normativa das águas, esta pesquisa permite observar que o Código das Águas foi o primeiro ato normativo específico que regulamentou este recurso e que a Política Nacional de Recursos Hídricos, Lei N. 9.433/97, o derrogou especificamente nos seus preceitos que acolhiam as águas como particulares, considerando-as eminentemente como águas públicas.

As categorias direito ao uso, proteção da qualidade foram as principais vinculadas as legislações que citam a água como elemento do conteúdo legal. A proteção legislativa dos recursos hídricos, sobre tudo a 
PNRH se apresenta robusta e denota a tentativa de romper com o paradigma da abundância de água, introduzindo o paradigma racional do uso da água, mostrando uma preocupação do legislador não só com o aspecto qualitativo das águas, como observado na legislação esparsa, mas também um cuidado em se proteger os recursos hídricos em seu aspecto quantitativo.

No entanto, em que pese verificar-se a existência de uma legislação eficiente de proteção às águas, a sua efetiva tutela só será alcançada na medida em ocorram mudanças culturais de conscientização por parte de toda a sociedade no sentido de contribuir para o processo do uso racional e da conservação desse precioso bem. Para evitar a crise da água, seriam necessários: evitar desperdício, interromper processos poluidores e criar novas maneiras de captação, controle e distribuição da água, tudo isso pautado em uma legislação séria e viável.

É incontestável que a situação dos recursos hídricos no mundo é grave e exige um planejamento emergencial, por meio de ações promovidas pelo governo voltadas à conscientização quanto ao consumo irracional, com efeito, ao longo da análise dos dispositivos resta clara a ideia reiterada de que sua intenção é alterar a cultura e o aproveitamento que a população destina a esse recurso fundamental, equiparado por vários autores em importância ao direito à vida.

\section{REFERÊNCIAS}

ALEXANDRINO, M.; PAULO, V.. Direito administrativo. São Paulo: Método, 2009.

ANTUNES, P. B.. Direito ambiental. Rio de Janeiro: Lumen Juris, 2001.

BARDIN, L.. Análise de conteúdo. São Paulo: 70, 2011.

BARRETO, A. M.. Território de águas na Amazônia: Ribeirinhos e o direito à coletiva da Terra. Juruá, 2019.

BRAGA, B.; FLECHA, R.; PENA, D. S.; KELMAN, J.. A reforma institucional do setor de recursos hídricos. In: BRAGA, $B$. REBOUÇAS, A. C.; TUNDISI, J. G.. Águas doces no Brasil: capital ecológico, uso e conservação. 3 ed. São Paulo: Escrituras, 2006. p.639-676.

BRASIL. Código das Águas Decreto n. 24.643, de 10 de julho de 1934. Brasília: ANA, 1934.

BRASIL. Constituição da República Federativa do Brasil, 1988. Brasília: DOU, 1988

BRASIL. Lei n. 9.433, de 08 de janeiro de 1997. Política Nacional de Recursos Hídricos. Brasília: DOU, 1997.

CASELLA, P. B.; ACCIOLY, H.; SILVA, G. E. N.. Manual de direito internacional público. 17 ed. São Paulo: Saraiva, 2009.

CARAMELLO, N.; SAURI PUJOL, D.. El Río: un protagonista oculto em el diálogo de las aguas. Mercator, Fortaleza, v.15, n.3, p.107-126, 2016.

CARAMELLO, N.; PUJOL, D. S.; PENHA, M.; PUJANTEL, J.; BOADA, M.. A conceitualização de atores e agentes hidrográficos: estudo de caso em bacias localizadas na Espanha e no Brasil. In: Amazônia contribuição cientifica para gestão hídrica. Ituiutaba: Barlavento, 2019. p.21-65.

CORRÊA, M. I.. Contribuição para uma história da regulamentação do setor de energia elétrica no Brasil: o Código de Águas de 1934 e o Conselho Nacional de Águas e Energia Elétrica. Política \& Sociedade, Florianópolis, v.1, n.6, p.255-291, 2005

ENKES, S. L.. Política Nacional de Recursos Hídricos e Sistema Nacional de Gerenciamento de Recursos Hídricos. Jus Navigandi, Teresina, v.8, n.64, p.1-10, 2003.

FIGUEREDO, D. M.. Hidrelétricas e Agronegócio na Bacia do Rio Teles Pires: Contradições e Conflitos no Uso da Água. In: Amazônia contribuição cientifica para gestão hídrica. Ituiutaba: Barlavento, 2019. p.92-132.

GUEDES, B. F. P.. Gestão participativa dos recursos hídricos uma análise da formação, da consolidação e do funcionamento do subcomitê da bacia hidrográfico do Ribeirão ad Mata. Dissertação (Mestrado em Engenharia Ambiental) - Universidade Federal de Ouro Preto, Ouro Preto, 2009.

IBGE. Instituto Brasileiro de Geografia e Estatística. Estimativas da população residente nos municípios brasileiros. Brasília: IBGE, 2018.

LIMA, J. A. V.; CARAMELLO, N. D. A.; CUNHA, G. D.; STACHIW, R.. Pequenas centrais hidrelétricas: externalidades de atores inseridos na Bacia Hidrográfica do Rio Branco e Colorado. Nature and Conservation, v.12, n.1, p.55-65, 2019. DOI: http://doi.org/10.6008/CBPC2318-2881.2019.001.0006 
MEZZAROBA, O. M. C. S.. Manual de metodologia da pesquisa no direito. 5 ed. São Paulo: Saraiva, 2009.

NUNES, A.; MOREIRA, C. O.; PAIVA, I. R.; CUNHA, L. S.. Territórios de Água. Coimbra: CEGOT, 2016.

ODAR, R. M. T.. Tipología de Las Investigaciones Jurídicas. Derecho y Cambio Social, v.43, n.13, p.1-37, 2016.

ONU. Organização das Nações Unidas. ONU Até $\mathbf{2 0 3 0}$ planeta pode enfrentar déficit de água de até $40 \%$, alerta relatório da ONU. São Paulo: ONU, 2020.

PENMAN, H. L.. Natural evaporation from open water, bare soil and grass. Proceedings of the Royal Society of London, v.193, n.34, p.120-146, 1948.
SILVA, J. A.. Direito Ambiental Constitucional. 11 ed. São Paulo: Malheiros, 2019.

RODRIGUES, G.. Direito Ambiental Positivo. Rio de Janeiro: ELSEVIER, 2008.

SANTILLI, J.. Aspectos jurídicos da Política Nacional de Recursos Hídricos. Brasília: Meio Ambiente, 2007.

TUCCI, C. E. M.. Desenvolvimento institucional dos recursos hídricos no Brasil. Revista de Gestão de Água da América Latina, Porto Alegre, v.2, n.2, p.81-93, 2005.

WOLKMER, M. F. S.; PIMMEL, N. F.. Política Nacional de Recursos Hídricos: governança da água e cidadania ambiental. Sequência, Florianópolis, v.10, n.67, p.165-198, 2013.

A CBPC - Companhia Brasileira de Produção Científica (CNPJ: 11.221.422/0001-03) detém os direitos materiais desta publicação. Os direitos referem-se à publicação do trabalho em qualquer parte do mundo, incluindo os direitos às renovações, expansões e disseminações da contribuição, bem como outros direitos subsidiários. Todos os trabalhos publicados eletronicamente poderão posteriormente ser publicados em coletâneas impressas sob coordenação da Sustenere Publishing, da Companhia Brasileira de Produção Científica e seus parceiros autorizados. Os (as) autores (as) preservam os direitos autorais, mas não têm permissão para a publicação da contribuição em outro meio, impresso ou digital, em português ou em tradução. 